\title{
Efeito fitotóxico do óleo volátil de Cleome guianensis Aubl. sobre o crescimento inicial de Senna occidentalis L.
}

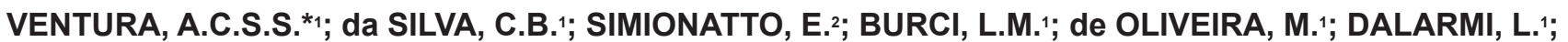
MIGUEL, O.G.'; MIGUEL, M.D.1

'Universidade Federal do Paraná, Departamento de Farmácia, Av. Lothario Meissner, 632, Curitiba-PR, 80210170. ' Universidade Estadual de Mato Grosso do Sul, Departamento de Química, Rua 275, Rua Emilio Mascolli, centro, Naviraí- MS, 79950-000, *Autor para correspondência: anaclarasans@gmail.com

\begin{abstract}
RESUMO: Aleloquímicos são substâncias liberadas por certas espécies vegetais no ambiente que influenciam a germinação e o desenvolvimento de outras plantas. O objetivo desse estudo foi avaliar o potencial fitotóxico de Cleome guianensis Aubl., bem como determinar o grau de estresse oxidativo causado em Senna occidentalis L. Para isso, o óleo das folhas de $C$. guianensis, nas concentrações $0,5 \mu \mathrm{g} / \mathrm{mL}, 1,0 \mu \mathrm{g} / \mathrm{mL}, 2,5 \mu \mathrm{g} / \mathrm{mL}$ e $5,0 \mu \mathrm{g} / \mathrm{mL}$, em solução de 5 $\mathrm{ml}$ foi testado em bioensaios de germinação e de crescimento da raiz primária e do hipocótilo de $S$. occidentalis. Os indivíduos de S. occidentalis foram macerados, homogeneizados e submetidos a ensaios de quantificação da catalase, peroxidase, SOD e de peroxidação lipídica. Os resultados indicam que todas as concentrações do óleo volátil causaram um efeito negativo sobre a germinação e crescimento de $S$. occidentalis. Na concentração $5,0 \mu \mathrm{g} / \mathrm{mL}$, houve $56 \%$ de inibição da germinação e $83 \%$ de inibição de crescimento do hipocótilo. Ainda, o óleo aumentou a atividade das enzimas induzidas pelo estresse oxidativo catalase, peroxidase e superóxido dismutase (SOD). Quanto à peroxidação lipídica, o óleo nas concentrações $1,0 \mu \mathrm{g} /$ $\mathrm{mL}, 2,5 \mu \mathrm{g} / \mathrm{mL}$ e $5,0 \mu \mathrm{g} / \mathrm{mL}$ aumentou a produção de malondialdeído. Sendo assim, conclui-se que C. guianensis apresenta aleloquímicos que influenciam na germinação e no crescimento de $S$. occidentalis, além de aumentar a atividade das enzimas catalase, peroxidase, SOD e a produção de malondialdeído em S. occidentalis. Dessa forma, sugere-se a realização de estudos sobre o perfil químico do óleo a fim de descobrir as substâncias responsáveis por tais resultados e consolidar o potencial fitotóxico de $C$. guianensis.
\end{abstract}

Palavras-chave: Alelopatia, bioherbicida, estresse oxidativo.

\begin{abstract}
Phytotoxic effect of Cleome guianensis Aubl. on the initial growth of Senna occidentalis L. Allelochemicals inhibit the germination and growth of other plants. The purpose of this study was to assess the phytotoxic potential of Cleome guianensis Aubl., as well as determine the degree of oxidative stress caused in Senna occidentalis L. For this purpose, oil from the leaves of $C$. guianensis in concentrations of $0.5 \mu \mathrm{g} / \mathrm{mL}, 1.0 \mu \mathrm{g} / \mathrm{mL}, 2.5 \mu \mathrm{g} / \mathrm{mL}$, and 5.0 $\mu \mathrm{g} / \mathrm{mL}$ were tested in bioassays on the germination and growth of S. occidentalis. Specimens of $S$. occidentalis were macerated, homogenized, and submitted to catalase, peroxidase, superoxide dismutase (SOD), and lipid peroxidation quantification tests. Results showed that all concentrations of the volatile oil had a negative effect on $S$. occidentalis germination and growth. In the $5.0 \mu \mathrm{g} / \mathrm{mL}$ concentration, the oil inhibited $56 \%$ of germination and $83 \%$ of hypocotyl growth. In addition, the oil increased the activity of the enzymes induced by oxidative stress: catalase, peroxidase, and superoxide dismutase SOD. For lipid peroxidation, the oil in the 1.0 $\mu \mathrm{g} / \mathrm{mL}, 2.5 \mu \mathrm{g} / \mathrm{mL}$ and $5.0 \mu \mathrm{g} / \mathrm{mL}$ concentrations increased the production of malondialdehyde. In addition, C. guianensis presents allelochemicals that influence the germination and growth of $S$. occidentalis, also enhancing activity of the catalase, peroxidase, and SOD enxymes, as well as malondialdehyde production in S. occidentallis. Hence, further studies of the chemical profile of this oil should be performed in order to discover which allelochemicals are responsible for these results and consolidate the phytotoxic potential of $C$. guianensis.
\end{abstract}

Keywords: allelopathy, bioherbicide, oxidative stress. 


\section{INTRODUÇÃO}

Devido aos efeitos adversos decorrentes da utilização de herbicidas sintéticos, tais como a acumulação de resíduos tóxicos no ambiente, o desenvolvimento de resistência pela planta e as consequências indesejadas para os organismos não alvo (Jana \& Biswas, 2011), muitos pesquisadores vêm priorizando estudos sobre agricultura sustentável, em busca de substâncias vegetais para serem utilizadas no controle de plantas daninhas (Dayan et al., 2009; Cantrell et al., 2012). Alguns metabólitos, majoritariamente provenientes do metabolismo secundário, liberados por espécies vegetais, denominados aleloquímicos, interferem na sobrevivência de outros vegetais no ambiente, influenciando no seu crescimento e induzindo, como defesa, o estresse oxidativo (Bogatek \& Gniazdowska, 2007). Consequentemente, os aleloquímicos agregam potencial para utilização na agricultura. Muitos desses aleloquímicos são rapidamente biodegradados no ambiente, o que reduz o risco de a substância vir a ser fonte de contaminação (Jana \& Biswas, 2011). No Brasil, estudos no controle de Senna occidentallis L., conhecida popularmente como "fedegoso" ou "matapasto", residem no fato de que sementes dessa espécie apresentam um histórico de contaminação de plantações de forrageiras, ou seja, de plantas que servem como alimento para herbívoros. A ingestão de sementes de $S$. occidentalis por bovinos e aves leva a degeneração das suas fibras musculares, sendo, portanto, S. occidentalis, tóxica (Komer et al., 1994; Haraguchi et al., 1998).

Cleome é o maior gênero da família Cleomaceae, englobando 180 a 200 espécies (Aparadh et al., 2012) e a esse gênero pertence a espécie Cleome guianensis Aubl.. C. guianensis é uma erva ereta de 20 a $60 \mathrm{~cm}$ de altura, folhagens bem desenvolvidas e flores de cor amarelo claro, sendo encontrada em locais rochosos e sedimentares (Silva et al., 2009). Essa espécie é de ampla distribuição, está presente desde os Estados Unidos, encosta oeste do México, Guatemala, Cuba ocidental, Colômbia, Guiana Inglesa até o Brasil, onde é encontrada na região norte (Amazonas, Amapá, Pará, Roraima e Tocantins) na região nordeste (Alagoas, Bahia, Ceará, Maranhão, Paraíba, Pernambuco, Piauí, Rio Grande do Norte e Sergipe), na região Centro-Oeste (Goiás, Mato Grosso do Sul e Mato Grosso) e na região Sudeste (Minas Gerais) (Martius et al., 2005).

Estudos têm demonstrado os benefícios provenientes da utilização do gênero Cleome no âmbito da saúde (McNeil et al., 2010, 2012; Hashem, 2011; Narendhirakannan et al., 2007; Bbowankule et al., 2008; Devi et al., 2002; Dixit \& Gupta, 2009; Motnal et al., 2011) e também evidenciado o seu efeito fitotóxico (Jana \& Biswas, 2011), porém nenhum dado a respeito da atividade fitotóxica da espécie C. guianensis foi postulado.

A importância do gênero Cleome no Brasil reside no fato de que folhas e raízes de suas espécies são utilizadas na medicina tradicional como estomáquicas e estimulantes do aparelho digestivo, eficazes na leucorréia. Externamente, utiliza-se o suco das folhas para a redução de otites supuradas e as raízes são eficazes no tratamento de bronquites asmáticas (Leal et al., 2007). No gênero Cleome são relatadas a presença de alcalóides (Delaveau et al. 1973), flavonóides (Sharaf et al., 1997; Mahmoud et al., 2003), fenoxicoumarina (Ramachandran, 1979), diterpenos cembranos (Collins et al., 2004), Esteróides glicosídeos (Srivastava, 1982), triterpenos dammaranos (Ahmed et al., 2001) e sais de amônio quaternários (Mc Lean et al., 1996).

Sendo assim, o objetivo desse estudo foi avaliar o potencial fitotóxico do óleo volátil das folhas de C. guianensis sobre a espécie daninha $S$. occidentalis, por meio de ensaios sobre o crescimento inicial, além de determinar a ocorrência de alterações no estresse oxidativo de S. occidentalis como defesa devido à liberação de aleloquímicos por C. guianensis.

\section{MATERIAL E MÉTODO}

Folhas de Cleome guianensis Aubl. (Cleomaceae) foram coletadas em 12 de abril de 2011, as 8:35 h, no Vale do Urucum em Corumbá, MS, coordenadas $57^{\circ} 03^{\prime} 02,3^{\prime \prime} \mathrm{W}$ e $19^{\circ} 01^{\prime} 04,7$ $\mathrm{S}$, e um exemplar foi incorporado no herbário da Universidade Federal de Mato Grosso do Sul (Voucher número 22853). As folhas coletadas foram submetidas a processos de hidrodestilação por quatro horas em aparelho do tipo Clevenger modificado, seguido pela extração exaustiva do destilado com hexano. Após a remoção do solvente, o rendimento do óleo bruto foi de $0,65 \%$ em relação ao material fresco.

Para o preparo das soluções, o óleo volátil foi emulsionado com Tween $80^{\mathrm{a}} 1,0 \%$ e dissolvido em água destilada para a obtenção da solução estoque na concentração de $5 \mu \mathrm{g} / \mathrm{mL}$. As demais concentrações $(0,5 ; 1,0$ e 2,5$)$ foram preparadas por diluição. Como controle, foi utilizada uma solução de Tween 80 a 1,0\%. Para os bioensaios de germinação, as placas de Petri (4,0 cm de diâmetro) contendo papel filtro Whatman $n^{\circ} 1,0$, autoclavadas, receberam $5,0 \mathrm{~mL}$ de água destilada e 30 sementes de $S$. occidentalis distribuídas aleatoriamente, com quatro repetições para cada solução. Após a semeadura, 3,0 ml da solução de cada concentração do óleo foram distribuídos em dois papéis-filtro e

Rev. Bras. PI. Med., Campinas, v.18, n.1, supl. I, p.349-355, 2016. 
colados na tampa da placa evitando o contato direto com as sementes (Alves et al., 2004). Neste ensaio de germinação e crescimento inicial, a semente não necessita de luz para germinar, tendo em vista que no processo germinativo a respiração é o processo que inclui gasto de energia para o crescimento inicial, não sendo a luz necessária para que ocorra a germinação. Como controle, procedimento similar foi utilizado, porém, com ausência das soluções contendo os óleos voláteis. As placas de Petri foram fechadas, envolvidas com filme plástico e levadas a uma câmara de germinação do tipo BOD, com condições de luz, umidade e temperatura constantes: $30^{\circ} \mathrm{C}$ e fotoperíodo de 12 horas (Brasil, 2009). Após sete dias de incubação, foi determinada a porcentagem de germinação e a porcentagem de crescimento da raiz primária e do hipocótilo. Em seguida, as plântulas foram utilizadas para a determinação do peso seco (Macias et al., 2000).

Para a avaliação das enzimas envolvidas no estresse oxidativo, cerca de dez plântulas submetidas aos diferentes tratamentos foram maceradas em almofariz com nitrogênio liquido, e o pó resultante foi homogeneizado com tampão fosfato de Sódio, pH 7,0, 50 mM, contendo EDTA 2 mM e PVP 1,0\% (Marques \& Xavier-Filho, 1991). Os extratos foram centrifugados a $4.000 \mathrm{rpm}$ e em seguida os sobrenadantes foram acondicionados em freezer $\mathrm{a}-18^{\circ} \mathrm{C}$ até o momento das análises. As preparações para a extração das enzimas foram realizadas a $4{ }^{\circ} \mathrm{C}$.

A quantidade total de proteínas solúveis presentes nas plântulas submetidas a diferente concentração dos óleos voláteis foi determinada de acordo com Bradford (1976), onde concentrações de Albumina sérica bovina foram utilizadas como referência, sendo adicionado o reagente em $50 \mu \mathrm{l}$ de extrato enzimático, e as leituras realizadas a $594 \mathrm{~nm}$.

Para a avaliação do estresse oxidativo, foram realizados ensaios enzimáticos da catalase, peroxidase, peroxidação lipídica e superóxido dismutase. A atividade da catalase foi medida em um meio contendo $67 \mathrm{mM}$ de tampão fosfato de

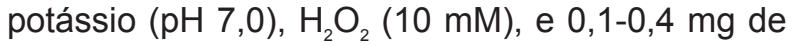
proteína do extrato enzimático. $\mathrm{O}$ consumo de $\mathrm{H}_{2} \mathrm{O}_{2}$ foi monitorado a $240 \mathrm{~nm}\left(\varepsilon, 0,036 \mathrm{mM}^{-1} \mathrm{~cm}^{-1}\right)$ (Aebi, 1984).

A atividade da peroxidase (POD) foi medida em um meio contendo tampão fosfato de Potássio $25 \mathrm{mM}(\mathrm{pH} 6,8), \mathrm{H}_{2} \mathrm{O}_{2}(10 \mathrm{mM})$ guaiacol $(2,6 \mathrm{mM})$ e $0,1-0,4 \mathrm{mg}$ de proteína do extrato enzimático. A formação de Tetraguaicol $\left(\varepsilon, 25,5 \mathrm{mM}^{-1} \mathrm{~cm}^{-1}\right)$ foi monitorada a $470 \mathrm{~nm}$ (Pütter, 1974).

Atividade de superóxido dismutase (SOD) foi medida de acordo com Giannopolitis \& Ries (1977). O meio continha tampão fosfato de potássio $50 \mathrm{mM}(\mathrm{pH} 7,8)$, L- metionina $6,5 \mathrm{mM}$, nitroblue tetrazolium $150 \mathrm{uM}$, riboflavina $4 \mu \mathrm{M}$ e $0,02-0,1$ mg de proteína do extrato enzimático. A reação foi iniciada pela ativação de uma luz ( $20 \mathrm{~W}$ ), iluminando o meio durante 20 minutos a $30^{\circ} \mathrm{C}$. Uma unidade de atividade de SOD $(U)$ foi definida como a quantidade de enzima necessária para causar uma inibição de $50 \%$ da taxa de fotorredução (NBT) a $560 \mathrm{~nm}$, e os resultados foram expressos como unidades de SOD. $\mu$ g. proteína-1

A peroxidação lipídica foi medida em um meio contendo $0,1 \%$ de ácido tricloroacético, $0,5 \%$ de ácido tiobarbitúrico e 0,1-0,4 mg de proteína do extrato enzimatico (Gomes-Junior et al., 2006). No momento da leitura, as amostras foram centrifugadas a 20.000 rpm durante 5 minutos e a absorbância do sobrenadante foi lida a $534 \mathrm{~nm}$. A atividade foi expressa como porcentagem de MDA produzidos, medida do estímulo de peroxidação lipídica.

As atividades das enzimas foram calculadas segundo Bracht et al. (2003). Para cada uma das enzimas descritas foi acrescentado o extrato enzimático e os reagentes específicos para a atividade avaliada. A absorbância dessas amostras foi monitorada durante 0 a 9 minutos e em seguida foi plotado um gráfico para cada dosagem enzimática, para obtenção da variação da tangente [a tg $=\Delta \mathrm{A} /$ $\Delta \mathrm{t}$ ] (onde: $\Delta \mathrm{A}=\mathrm{a}$ variação da absorbância; $\Delta \mathrm{t}=\mathrm{a}$ variação do tempo em minutos). Após as leituras das absorbâncias das enzimas, a atividade foi calculada em $\mu \mathrm{mol}$. min $^{-1}$ [Atividade $\left(\mu \mathrm{mol} \mathrm{min}{ }^{-1}\right)=\mathrm{vol}$ de incubação $x \alpha \operatorname{tg}\left(\min { }^{-1}\right) / \epsilon=$ unidades de enzima] (onde: $\epsilon=$ Coeficiente de extinção molar da enzima).

Todos os ensaios foram realizados em triplicata, os dados foram submetidos à análise de variância e, quando os efeitos dos tratamentos mostraram-se significativos ( $p<0,05)$ em relação ao controle, as médias foram comparadas pelo teste de Dunnet.

Nos gráficos, os resultados são representados em porcentagem em relação ao controle, sendo que o zero representa o controle, valores positivos representam estímulo e valores negativos representam inibição (Macias et al., 2006).

\section{RESULTADO E DISCUSSÃO}

Os resultados obtidos a partir dos bioensaios de germinação e crescimento inicial (Figura 1) demonstraram que os óleos voláteis das folhas de C. guianensis possuem ação fitotóxica sobre $S$. occidentallis, visto que a germinação (Figura 1a) das sementes dessa espécie se mostrou inibida em todas as concentrações testadas, com maior efeito para a concentração de $5,0 \mu \mathrm{g} / \mathrm{mL}(56 \%$ de inibição). Após sete dias de incubação com os óleos de C. guianensis, a raiz primária (Figura $1 \mathrm{~b}$ ) e o hipocótilo (Figura 1c) mostraram- se reduzidos,

Rev. Bras. PI. Med., Campinas, v.18, n.1, supl. I, p.349-355, 2016. 
com valores de inibição da raiz primária superiores a $50 \%$ para as concentrações de $1,0 \mu \mathrm{g} / \mathrm{mL}(54 \%$ de inibição); $2,5 \mu \mathrm{g} / \mathrm{mL}$ (61\% de inibição) e 5,0 $\mu \mathrm{g} /$ $\mathrm{mL}$ (83\% de inibição), e com valores de inibição do hipocótilo superiores ou iguais a $50 \%$ para as concentrações de $2,5 \mu \mathrm{g} / \mathrm{mL}$ ( $50 \%$ de inibição) e $5,0 \mu \mathrm{g} / \mathrm{mL}$ ( $57 \%$ de inibição). Sugere-se, dessa forma, que algum metabólito presente no óleo de C. guianensis pode ser responsabilizado por causar esse efeito negativo sobre o crescimento da raiz primária e do hipocótilo de $S$. occidentalis. Todas as concentrações afetaram o peso seco (Figura 1d) das plântulas de $S$. occidentalis, entretanto esse efeito inibitório não foi igual ou superior a $50 \%$.

Outras espécies do gênero Cleome também já tiveram sua atividade alelopática comprovada. Jana \& Biswas (2011) isolaram das raizes de Cleome viscosa o ácido lacto nonanoico, responsável pela ação inibitória dessa planta sobre sementes de arroz, mostarda e de grama. Da mesma forma, o extrato metanólico das vagens de Cleome arabica exerceu um potente efeito negativo na germinação das sementes de alface, bem como no crescimento dessas plântulas, devido a danos celulares na raiz correlacionados a redução mitótica (Ladhari et al., 2014). Portanto, sugere-se que algumas espécies do gênero Cleome concorram pela sobrevivência no ambiente liberando aleloquímicos.

A análise do estresse oxidativo (Figura 2) demonstrou que as concentrações dos óleos voláteis de $C$. guianensis alteraram a atividade das enzimas antioxidantes estudadas em S. occidentalis. A atividade da catalase (Figura 2a) e peroxidase (Figura 2b) aumentou em função das concentrações dos óleos voláteis. A concentração de $5,0 \mu \mathrm{g} / \mathrm{mL}$ aumentou a atividade da catalase e peroxidase em $2,2 \mu \mathrm{mol} \cdot \mathrm{H}_{2} \mathrm{O}_{2} \cdot \mathrm{min}^{-1}$ e $6,3 \mu \mathrm{mol}$.tetraguaiacol.min ${ }^{-1}$, respectivamente. Embora a concentração de 0,5 $\mu \mathrm{g} / \mathrm{mL}$ não tenha afetado a peroxidação lipídica (Figura 2c) em S. occidentallis, as concentrações de $1,0 \mu \mathrm{g} / \mathrm{mL}, 2,5 \mu \mathrm{g} / \mathrm{mL}$ e $5,0 \mu \mathrm{g} / \mathrm{mL}$ aumentaram a produção de malondialdeído, e este efeito pode ser decorrente da toxicidade. De maneira similar ao que ocorreu nos testes envolvendo as enzimas catalase e peroxidase, a enzima SOD (Figura 2d) se mostrou aumentada nos indivíduos de $S$. occidentalis em todas as concentrações do óleo volátil de $C$. guianensis. O maior valor para a atividade da enzima
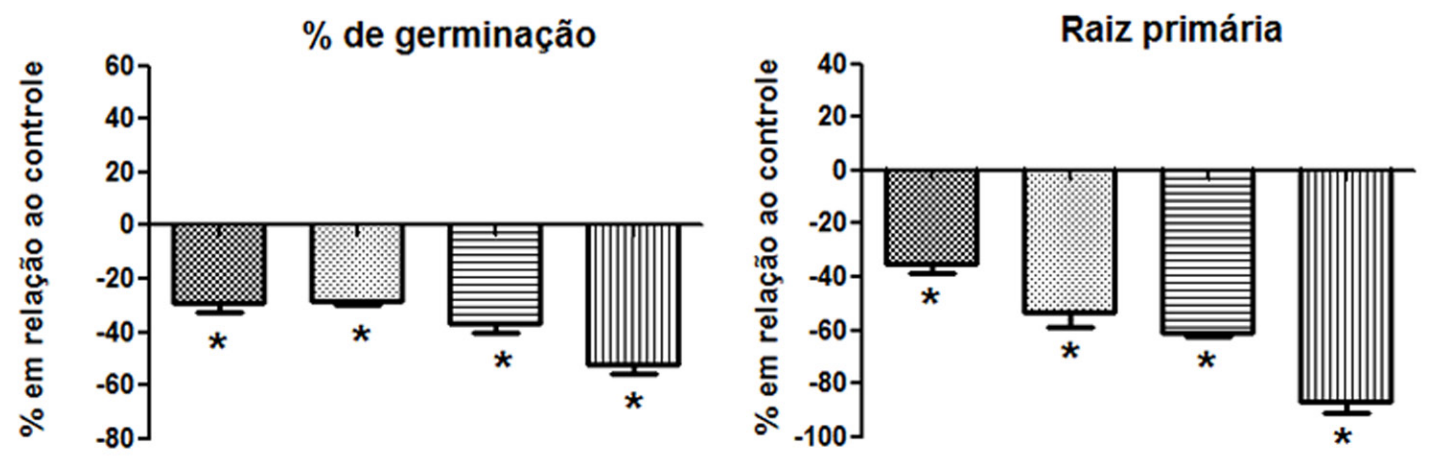

$0,5 \mu \mathrm{g} / \mathrm{mL}$ 圆 $1,0 \mu \mathrm{g} / \mathrm{mL}$ 目 $2,5 \mu \mathrm{g} / \mathrm{mL}$ 而 $5,0 \mu \mathrm{g} / \mathrm{mL}$
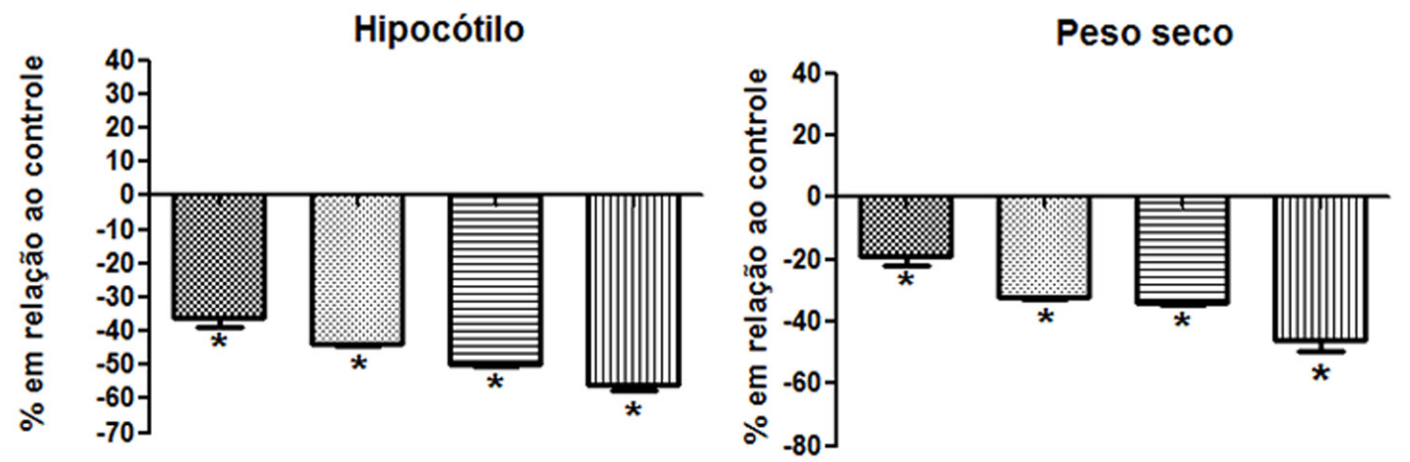

$0,5 \mu \mathrm{g} / \mathrm{mL} \times 1,0 \mu \mathrm{g} / \mathrm{mL}$ 目 $2,5 \mu \mathrm{g} / \mathrm{mL}$ 떼 $5,0 \mu \mathrm{g} / \mathrm{mL}$

FIGURA 1. Efeito dos óleos voláteis de C. guianensis sobre o crescimento inicial de $S$. occidentallis. (a) porcentagem de germinação (b) raiz primária (c) hipocótilo (d) peso seco. Dados expressos em percentual em relação ao controle. *A média do tratamento difere significativamente em comparação com a média do controle, pelo teste de Dunnet $(p<0,05)$.

Rev. Bras. PI. Med., Campinas, v.18, n.1, supl. I, p.349-355, 2016. 
SOD foi verificado para a concentração $5,0 \mu \mathrm{g} / \mathrm{mL}$, datando $5,9 \mathrm{U} \cdot \mathrm{mg}^{-1}$. O aumento da atividade das enzimas catalase, peroxidase, SOD e também da atividade de malondialdeído em S. occidentallis pode ser atribuído a ação de substâncias presentes no óleo de C. guianensis, responsáveis por estimular reação de defesa ao influenciar no estresse oxidativo de S. occidentalis.

Recentemente, foi sugerido que aleloquímicos influenciam no crescimento das plantas vizinhas devido a indução do estresse oxidativo (Bogatek \& Gniazdowska, 2007). Porque, embora as reações de oxidação sejam cruciais para a vida, elas também podem ser danosas. Assim, as plantas mantêm um complexo sistema antioxidante composto por enzimas como glutationa redutase, ascorbato peroxidase, catalase, SOD e peroxidases, para eliminar radicais tóxicos produzidos durante o estresse oxidativo e manter-se viva durante exposição a condições adversas (Haribabu \& Sudha, 2011).

Oracz et al, (2007), por exemplo, enfatizaram que o aumento da atividade enzimática do sistema antioxidante em sementes de mostarda submetidas ao extrato de girassol não foi suficiente para protegêlas dos danos desencadeados pelas espécies reativas de oxigênio. A atividade de radicais livres e da catalase também se mostrou alterada nas raízes de tomate em contato com a espécie Callicarpa accuminata (Cruz-Ortega et al., 2002), bem como a atividade das enzimas glutationa redutase, SOD, ascorbato peroxidase, e peroxidase de Lycopersicon esculentum submetido a Siyos deppei (Lara-Nunez et al., 2006).

A composição dos óleos voláteis das espécies pertencentes ao gênero Cleome é bastante diversa e pouco se conhece a respeito das atividades exercidas especificamente por seus constituintes. O óleo das partes aéreas de $C$. serrata coletadas na Jamaica nos estudos de McNeil et al. (2012) apresentou 14 componentes, dentre os quais os mais abundantes foram (Z)-fitol $(53,0 \%)$ e 2-tilhexil-ftalato (DEPH) $(14,7 \%)$. Da mesma forma, (Z)- fitol foi o constituinte mais abundante presente no óleo extraído das partes aéreas de $C$ spinosa da Jamaica, sendo responsável por 31,3\% do óleo. No mesmo estudo, quando se extraiu o óleo somente das folhas dos indivíduos, o (Z)-fitol
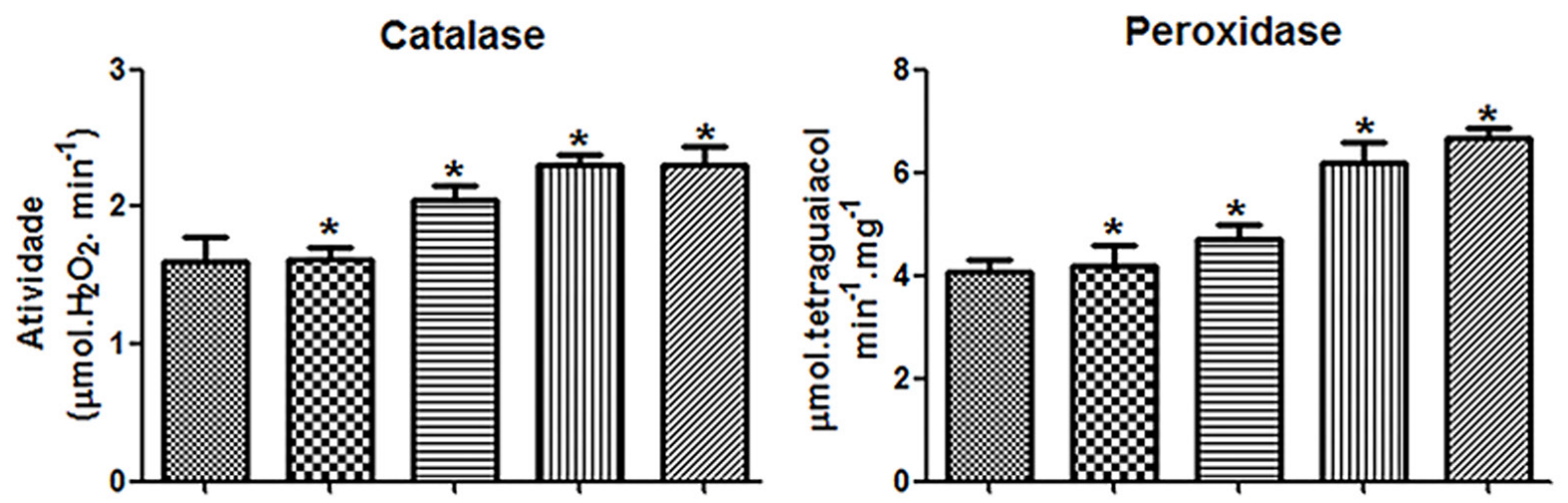

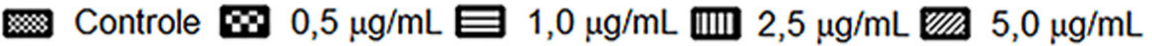

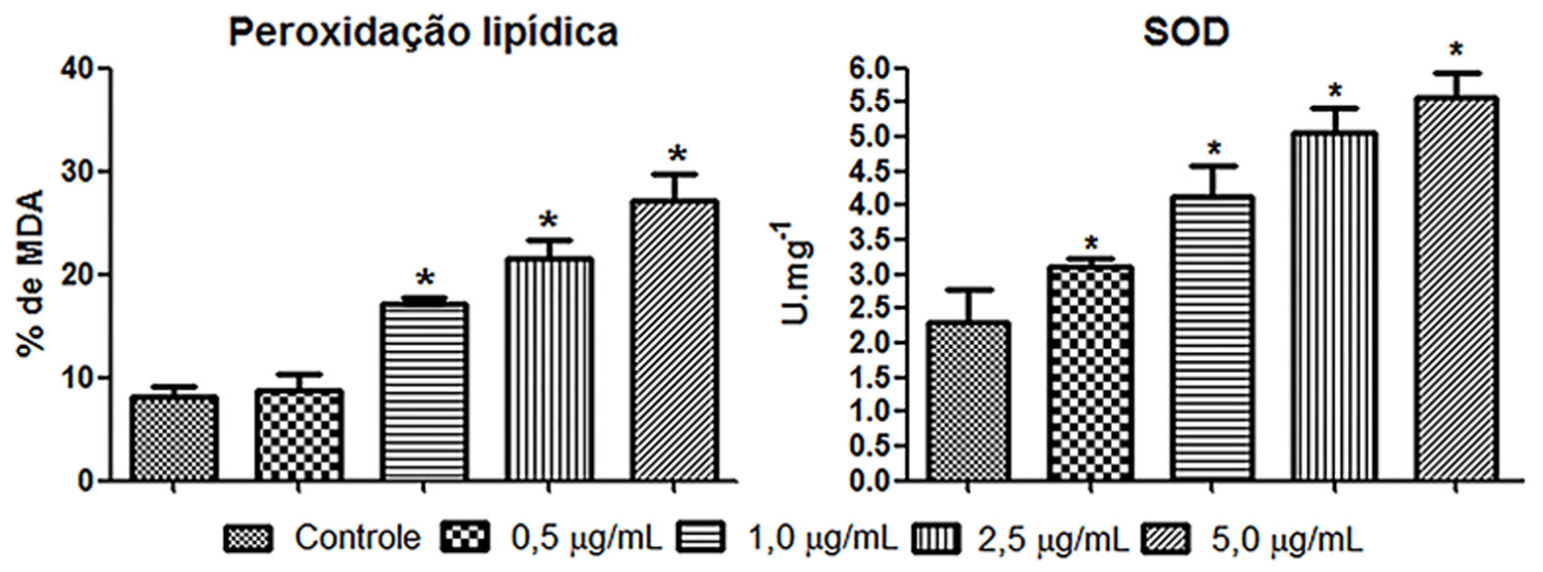

FIGURA 2. Efeito dos óleos voláteis de C. guianensis sobre o estresse oxidativo em plântulas de S. occidentallis. (a) Catalase (b) peroxidase (c) peroxidação lipídica (d) SOD. *A média do tratamento difere significativamente em comparação com a média do controle, pelo teste de Dunnet $(p<0,05)$. 
ainda se manteve como o constituinte presente em maior quantidade (19,5\%) (McNeil, 2010). Já o óleo essencial das partes aéreas de C. brachycarpa, coletadas no Irã, apresentou como componentes majoritários tunbergol $(46,1 \%)$ seguido pelo alfaeudesmol (12,7\%) (Rassouli \& Dadras, 2014). Também do Irã, o óleo proveniente das partes aéreas de C. coluteoides apresentou como componentes majoritários piperitone $(40,4 \%)$ e decanal $(18,7 \%)$ (Mazloomifar et al., 2003).

Da mesma forma, é importante observar que, mesmo quando se considera o óleo de somente uma espécie, ocorre variação na sua composição dependendo do indivíduo analisado, pois muitos fatores, tais como variação geográfica, condições do ambiente (como irrigação, incidência de luz e tipo de solo), época de colheita, idade da planta, fatores genéticos e fisiológicos influenciam nesse aspecto.

\section{CONCLUSÃO}

O óleo das folhas de C. guianensis, interferiu na germinação e no crescimento inicial de S. occidentallis, além de aumentar a atividade das enzimas catalase, peroxidase e SOD envolvidas no combate ao estresse oxidativo. Sendo assim, o óleo das folhas de C. guianensis pode ser útil para o manejo dessa espécie daninha. Entretanto, são necessários estudos que demonstrem o perfil químico deste óleo volátil para auxiliar em bioensaios a fim de identificar substâncias presentes no óleo com potencial fitotóxico.

\section{AGRADECIMENTO}

Os autores agradecem à Capes, CNPq e FUNDECT, pela concessão de bolsas e auxilio financeiro na execução do projeto.

\section{REFERÊNCIA}

AEBI, H. Catalase in vitro. Methods in Enzymology, v. 105, p. 121-6, 1984.

AHMED, A. A. et al. Acetoxycleomblynol A from Cleome amblyocarpa. Journal of Natural Products, v. 64, p. 106-7, 2001.

ALVES, M.D.C.S. et al. Alelopatia de extratos voláteis na germinação de sementes e no comprimento da raiz de alface. Pesquisa Agropecuária Brasileira, v. 39, p. 1083-86, 2004.

APARADH, V.T. et al. Taxonomy and physiological studies in spider flower (cleome species): a critical review. Plant Sciences Feed, v. 2, n. 3, p. 25-46, 2012.

BBOWANKULE, D.U. et al. Modulation of inflammatory mediators by coumarinolignoids from Cleome viscosa in female swiss albino mice. Inflammopharmacology, v. 16, n. 2, p. 272-7, 2008.

BOGATEK, R.; GNIAZDOWSKA, A. ROS and phytohormones in plant-plant allelopathic interaction. Plant signaling and behavior, v. 2, n. 4, p. 317-8, 2007.

BRACHT, A. et al. Enzimas. In: BRACHT, A.; ISHIIIWAMOTO, E.L. Métodos de laboratório em Bioquímica. 1. ed. Maringá: Manole, 2003, p. 103-137.

BRADFORD, M.M. A rapid and sensitive method for the quantitation of microgram quantities of protein utilizing the principle of protein-dye binding. Analytical Biochemistry, v. 72, n. 1-2, p. 248-54, 1976.

BRASIL. Regras para a Análise de Sementes. 1. ed. Brasília: Ministério da Agricultura, Pecuária e Abastecimento, 2009. 399 p.

CANTRELL, C.L. et al. Natural products as sources for new pesticides. Journal of Natural Products, v. 75, $\mathrm{n}$. 6, p. 1231-42, 2012.

COLLINS, D.O. et al. New cembranes from Cleome spinosa. Journal of Natural Products, v. 67, p. 17983, 2004.

CRUZ-ORTEGA R. et al. Allelochemical stress produced by aqueous leachate of Callicarpa acuminata: effects on roots of bean maize and tomato. Physiologia Plantarum, v. 116, p. 20-7, 2002.

DAYAN, F.E. et al. Natural products in crop protection. Bioorganic \& Medicinal Chemistry, v. 17, n. 12, p. 4022-34, 2009.

DELAVEAU, P. et al. Alcaloïdes chez les Capparidaceae. Phytochemistry, v. 12, p. 2893-5, 1973.

DEVI, B.P. et al. Evaluation of anti-diarrheal activity of Cleome viscosa L. extract in rats. Phytomedicine, v. 9, n. 8, p. 739-42, 2002.

DIXIT, V.K.; GUPTA, N.K. Evaluation of hepatoprotective activity of $C$. viscosa Linn. extract. Indian journal of pharmacology, v. 9, n. 1, p. 36-40, 2009.

GIANNOPOLITIS, C.N.; RIES, S.K. Superoxide dismutases: I. occurrence in higher plants. Plant Physiology, v. 59, n. 2, p. 309-14, 1977.

GOMES-JUNIOR, R.A. et al. Antioxidant metabolism of coffee cell suspension cultures in response to cadmium. Chemosphere, v. 65, n. 8, p. 1330-7, 2006.

HARAGUCHI, M. et al. Muscle degeneration in chicks caused by Senna occidentalis seeds. Avian pathology journal of the W.V.P.A., v. 27, n. 4, p. 346-51, 1998.

HARIBABU, T.E.; SUDHA, P.N. Effect of heavy metals copper and cadmium exposure on the antioxidant properties of the plant Cleome gynandra. International Journal of Plant, Animal and Environmental Sciences, v. 1, n. 2, p. 80-7, 2011

HASHEM, M. Antifungal properties of crude extracts of five egyptian medicinal plants against dermatophytes emerging fungi. Mycopatologia, v. 172, n. 1, p. 37-46, 2011.

IJANA, A.; BISWAS, S.M. Lactan nonanoic acid, a new substance from Cleome viscosa with allelopathic and antimicrobial properties. Journal of biosciences, v. 36, n. 1, p. 27-35, 2011.

KOMER, G.D. et al. Coffe senna (S. occidentalis) poisoning in cattle in Brazil. Veterinary human toxicology, v. 36, n. 65, p. 541-5, 1994.

LADHARI, T. et al. The impact of tunisian capparidaceae species on cytologial, physiological and biochemical mechanisms in lettuce. South African Journal of Botany, v. 93, p. 222-30, 2014.

LARA-NUNEZ, A. et al. Allelochemical stress causes

Rev. Bras. PI. Med., Campinas, v.18, n.1, supl. I, p.349-355, 2016. 
inhibition of growth and oxidative damage in Lycopersicon esculentum Mill. Plant, Cell and Environment, v. 29, p 2009-16, 2006.

LEAL, R. S. et al. Perfil Etnobotânico de Cleome spinosa Jacq e Pavonia varians Moric. In: CONGRESSO BRASILEIRO DE QUÍMICA, 47., 2007, Natal. Meio digital. Natal: Associação Brasileira de Química, 2007. Pôster, 2007. n. 425.

MACIAS, A.F. et al. Search for a standard phytotoxic bioassay for allelochemicals. Selection of standard target species. Journal of Agricultural and Food Chemistry, v. 48, n. 6, p. 2512-21, 2000.

MACIAS A.F. et al. Sesquiterpene lactones as allelochemicals. Journal of Natural Products, v. 69, n. 5, p. 795-800, 2006.

MAHMOUD, N. I.; GAMAL-ELDEEN, A. M. Potential Antioxidant Activity of Flavonoids from Hypericum Triquetrifolium Turra. And Cleome Droserifolia (Forssk). Bulletin of the Pharmacy, v. 41, p. 107-15, 2003.

MARQUES, M.R.; XAVIER-FILHO, J. Enzymatic and inhibitory activities of cashew tree gum exudate. Phytochemistry, v. 30, n. 5, p. 1431-33, 1991.

MARTIUS, C.F.P. von et al. Flora Brasiliensis. Online. Campinas: Centro de Referência em Informação Ambiental, 2005. Disponível em: <florabrasiliensis.cria. org.br/>. Acessado em abril de 2016.

MAZLOOMIFAR, H. et al. Essential oil of Cleome coluteoides Boiss. from Iran. Journal of Essential Oil Research, v. 15, n. 5, p. 337-8, 2003.

MC LEAN, W.F.H. et al. Quaternary Ammonium Compounds in the Capparaceae. Biochemical Systematics and Ecology, v. 24, p. 427-34, 1996.

MCNEIL, M.J. et al. Chemical composition and antimicrobial activity of the essential oils from Cleome spinosa. Natural products communication, v. 5, n. 8, p. 23016, 2010.

MCNEIL, R. et al. Chemical composition and biological activity of the essential oil from jamaican Cleome serrata. Natural Products Communication, v. 7, n. 9, p. 1231-2, 2012.

MOTNAL, A.A. et al. Determination of bioactive markers in C. droserifolia using cell-based bioassays for antidiabetic activity and isolation of two novel active compounds. Phytomedicine, v. 19, n. 1, p. 38-41, 2011.

NARENDHIRAKANNAN, K.T. et al. Antiinflammatory and lysosomal stability actions of C. gynandra C. studied in adjuvant induced arthritic rats. Food and chemical toxicology, v. 45, n. 6, p. 1001-12, 2007.

ORACZ, K. et al. Induction of oxidative stress by sunflower pytotoxins in germinating mustard seeds. Journal of Chemical Ecology, v. 33, p. 251-64, 2007.

PÜTTER, J. Peroxidases. In: BERGMEYER, H.U. Methods of Enzymatic Analysis. Waltham: Academic Press, 1974. p.685-90.

RAMACHANDRAN, N.A.G. Cleosandrin, a novel 7-phenoxycoumarin from the seeds of Cleome isosandra. Indian Journal of Chemystry, v. 17B, p. 438-40, 1979.

RASSOULI, E.; DADRAS, O.G. The essential oil composition of Cleome brachycarpa Vahl ex DC. Journal of Essential Oil-bearing Plants, v. 17, n. 1, p. 158-63, 2014.

SHARAF, M. et al. Flavonoids of four Cleome and three Capparis species. Biochemical Systematics and Ecology, v. 25, p. 161-6, 1997.

SILVA, K.A. et al. Estudo florístico do componente herbáceo e relação com solos em áreas de caatinga do embasamento cristalino e bacia sedimentar, Petrolândia, PE, Brasil. Acta Botânica Brasílica, v. 23, n. 1, p. 100-10, 2009.

SRIVASTAVA, S.D. Chemical Constituents of Cleome Viscosa. Indian Journal of Chemistry: Section B Organic Chemistry Including Medicinal Chemistry, v. 21 B, p. 165-7, 1982.

Rev. Bras. PI. Med., Campinas, v.18, n.1, supl. I, p.349-355, 2016. 